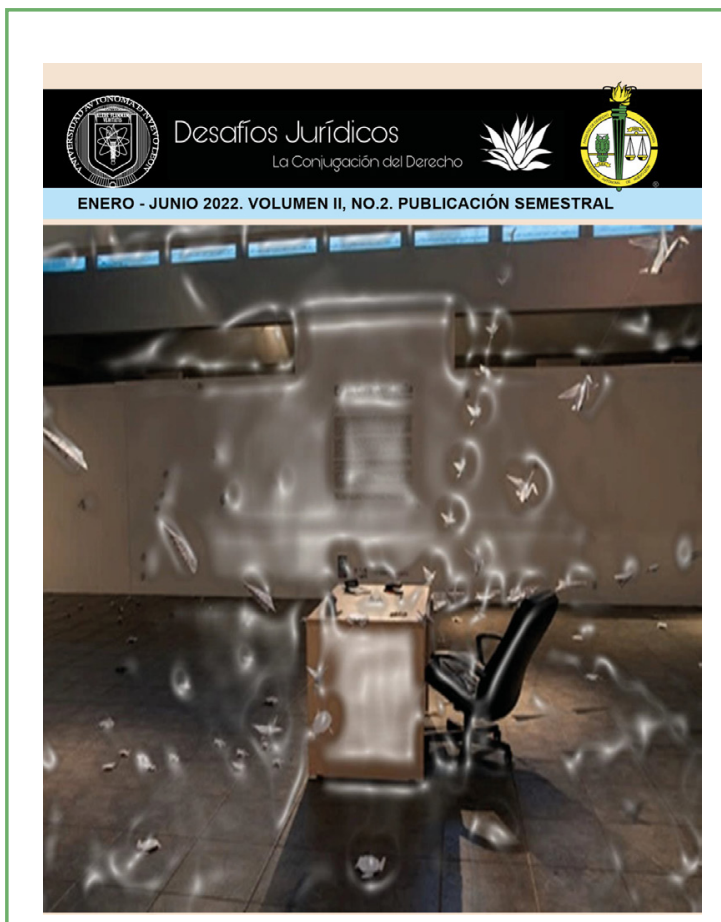

Detalles sobre la publicación, incluyendo instrucciones para autores e información para los usuarios en: https://desafiosjuridicos.uanl.mx/ index.php/ds

María Eugenia Martínez Flores \& Martha Alicia Vela Gámez (Facultad de Filosofía y Letras, Universidad Autónoma de Nuevo León.)

Análisis de Categorías Sociopragmáticas en Textos de Carácter Civil y sus Representación a través de la (Des) cortesía e Intensificación. pp. 32-55 Fecha de publicación en línea: 31 de enero del 2022.

Publicado en Desafíos Jurídicos La Conjugación del Derecho. Todos los derechos reservados. Permisos y comentarios, por favor escribir al correo electrónico: desafios.juridicos@uanl.mx

Desafíos Jurídicos La Conjugación del Derecho. Revista de temas contemporáneos sobre derecho, y sus conexiones en la vida cotidiana, Volumen 2, No. 2, enero-junio de 2022, es una publicación semestral de la Universidad Autónoma de Nuevo León, a través de la Facultad de Derecho y Criminología, editada en la Ciudad Universitaria, N.L, México. Con dirección en Cd. Universitaria, Av. De los Rectores s/n, San Nicolás de los Garza, N.L. C.P. 66451, Página electrónica de la revista: http://desafiosjiridicos.uanl.mx

Editora en jefe: Dra. Amalia Guillén Gaytán Reserva de Derechos al Uso Exclusivo del Título Volumen 2, No. 2, enero-junio de 2022, ISSN: en trámite ante el Instituto Nacional del Derecho de Autor. Responsable de la última actualización de este número: Mtro. Juan Alonso Martínez Arrieta.

Desafíos Jurídicos La Conjugación del Derecho aborda temas contemporáneos sobre derecho, y sus conexiones en la vida cotidiana, tiene como propósito constituirse en un foro de discusión académica que aborda la compleja, contradictoria y multicausal relación entre el derecho y la vida social. Desafíos Jurídicos se inscribe en el debate académico nacional e internacional en el ámbito de Derecho y su giro especial en las ciencias sociales e invita al análisis de diversas prácticas sociales y formas de organización y acción política desde una perspectiva multidisciplinaria que ponga énfasis en la defensa de los derechos y su aplicación. Los textos publicados incorporan métodos y problemas tratados desde el derecho, la sociología, la ciencia política, la economía, los estudios urbanos, la geografía, los estudios culturales, la antropología, la literatura y el feminismo, entre otros. Las opiniones expresadas por los autores no reflejan la postura del comité editorial.

Queda estrictamente prohibida la reproducción total o parcial de los contenidos e imágenes de la publicación sin previa autorización expresa de la revista.

DIRECTORIO INSTITUCIONAL

RECTOR: DR. SANTOS GUZMÁN LÓPEZ

SECRETARIO GENERAL: DR. JUAN PAURA GARCIA

DIRECTOR DE LA FACULTAD DE DERECHO Y CRIMINOLOGIA: MTRO. OSCAR P. LUGO SERRATO

REVISTA DESAFÍOS JURÍDICOS

DIRECTORA: Dra. Amalia Guillén Gaytán

CORDINADOR: Dr. Mario Alberto García Martínez

CORDINADOR DEL NÚMERO: Mtro. Juan Alonso Martínez Arrieta

ASISTENTE EDITORIAL: Mtra. Angélica Rubí Rodríguez Aguirre

ADMINISTRACIÓN DEL SITIO WEB: M.A. Daniel Vázquez Azamar

EDICIÓN TEXTUAL Y CORRECCIÓN DE ESTILO: Rosa María Elizondo Martínez

PINTURA DE LA PORTADA: M.A. Daniel Vázquez Azamar "En la otra ventanilla" @ 2022 


\section{Análisis de Categorías Sociopragmáticas en Textos de Carácter Civil y sus Representación a través de la (Des)cortesía e Intensificación}

Analysis of Socio-pragmatic Categories in Legal Civil Texts and their Representation through (Im)politeness and Intensification

Fecha de publicación en línea: 31 de enero del 2022

Por: María Eugenia Martínez* y Martha Alicia Vela Gamez** *https://orcid.org/0000-0001-5573-3592

Universidad Autónoma de Nuevo León

** https://orcid.org/0000-0002-2035-5875

Universidad Autónoma de Nuevo León

Resumen. En este trabajo se analizan las estrategias comunicativas de atenuación e intensificación en dos sentencias civiles - sentencia de divorcio y sentencia de adopción plena - emitidas en el Estado de Nuevo León, México. Para estudiar las estrategias atenuadoras se utilizan las propuestas de clasificación que plantea Briz (2001) y las estrategias de intensificación se analizan a partir de la clasificación hecha por Martha Albelda (2005). Para el análisis de las estrategias de (des)cortesía e imagen se utilizarán los modelos de Brown y Levinson (1987), Briz $(2001,2003)$, Albelda (2005) quienes plantean en sus modelos teóricos generalizaciones de cómo funciona la cortesía en los distintos niveles de la lengua, y el concepto de imagen de autonomía y afiliación se analizan a partir de los conceptos teóricos planteados por Bravo (2004, 2010).

De acuerdo con María Bernal (2010) en el discurso jurídico, dado que se trata de un lenguaje de registro formal por ser oficial y por quienes lo emiten se presupone que la atenuación a través de la cortesía está presente de modo automático. Su naturaleza además debe ser un mecanismo retórico para convencer, obtener beneficio, persuadir, y asimismo, cuidar las relaciones interpersonales y sociales de los individuos involucrados en un proceso jurídico. En el discurso jurídico cada uno de los actores en el proceso de la demanda tienen propósitos claros en su rol de hablante y oyente y su intención en el acto de habla de un proceso legal.

Palabras clave: discurso jurídico, atenuación, intensificación, cortesía, descortesía, estrategias de imagen y afiliación. 
Abstract. This article analyzes the communicative strategies of mitigation and intensification in two civil sentences - a divorce sentence and a full adoption sentence - issued in the State of Nuevo Leon, Mexico. The study founds the mitigation strategies on Briz's (2001) classification proposals, and the study of intensification strategies on Martha Albelda's (2005) classification. The analysis of (im)politeness and image strategies follows the models of Brown and Levinson (1987), Briz (2001, 2003), and Albelda (2005); their theoretical models state generalizations of how politeness works in the different language levels, as well as the image of autonomy and affiliation's study grounds on Bravo's $(2004,2010)$ theoretical framework.

María Bernal (2010) notes that legal discourse assumes that mitigation is observed automatically through politeness considering the language's formal register and those authorities who issue it. Its nature must be a rhetorical mechanism to convince, benefit, persuade, and also take care of the interpersonal and social relationships of the legal process' participants. In the legal discourse, petitioners within a lawsuit has a purpose in their roles as speaker and listener and their intention in a legal process' speech act.

Keywords: legal discourse, mitigation, intensification, (im)politeness, image, and affiliation strategies.

\section{INTRODUCCIÓN}

En el acto comunicativo que se presenta en el discurso jurídico y dado a los involucrados en un proceso legal, estos buscan como finalidad alcanzar como objetivo persuadir a su oponentes con diversas estrategias y conseguir su propósito en una situación de demanda. La demanda consiste en la declaración de voluntad de una persona, que se expresa formalmente en un escrito dirigido a un juzgado, en donde se solicita que se incoe un proceso y comience su tramitación. A este acto se le llama la presentación de la demanda y, a partir de este momento, el perjudicado se convierte en actor o demandante de la persona contra la que se inicia el proceso -el demandado-que es la parte a la que considera responsable del perjuicio que él ha sufrido (Alcaraz Varó \& Hughes, 2002)'.

Desde esta perspectiva, el proceso de demandar ya implica en sí un proceso en el que la imagen de quien inicia dicho proceso se ve amenazada, por lo cual se recurre a la atenuación del discurso por medio de la cortesía para así mitigarlo y tener como resultado un mecanismo retórico para convencer, obtener un beneficio, persuadir, y a la vez, cuidar las relaciones interpersonales y sociales de los individuos involucrados en un proceso jurídico. Todo acto comunicativo, y en este caso el discurso jurídico, tiene como finalidad alcan-

1 Alcaraz Varó, E., \& Hughes, B. (2002). El español jurídico. Barcelona: Ariel. 
zar un objetivo por el cual el hablante busca de alguna manera persuadir a su oponente a través del lenguaje y así conseguir lo que se propone. Estas representaciones comunicativas de un proceso demanda y la interrelación comunicativa de los involucrados en las que emplean mecanismos de atenuación, (des) cortesía e intensificación se abordan en el presente trabajo desde una perspectiva de los estudios de la sociopragmática.

En este trabajo se busca por lo tanto, dar a conocer los tipos de estrategias de (des)cortesía y de intensificación que se producen en las sentencias civiles, ya que estos elementos en el texto están claramente representados en la tipología textual jurídica. Held $(1989)^{2}$ considera que la atenuación y la intensificación son estrategias de minimización y maximización que no se consideran como estrategias válidas y que su función en ambas es proteger la imagen de los involucrados en un proceso comunicativo.

\section{MARCO TEÓRICO}

\subsection{La naturaleza lingüístico discursiva del texto jurídico}

Es importante destacar que el lenguaje jurídico, dentro de los lenguajes de especialidad, se desenvuelve dentro de una situación llevada a cabo por los profesionales del derecho, se dice que posee un alto grado de especificidad y es extremadamente conservador a diferencia de otros lenguajes que presentan mayor dinamismo en su desarrollo debido a los con-

2 Held, G. (1989). On the role of maximization in verbal politeness, Multilingua 8-2/3, pp. 167-206. tinuos avances tecnológicos que obligan a la creación de nuevos conceptos en un área de conocimiento específico (Borja, 2000)․․ Este tipo de textos que son meramente normativos, a diferencia de los narrativos, poéticos, filosóficos o científicos, se caracterizan por su valor autoritativo derivados de las instancias que los emiten y por presentar una función prescriptiva, destinada a orientar el comportamiento de terceros (Borja, 2000).

De esto deriva que utilizan elementos lingüísticos y terminológicos que a menudo resulta difícil de comprender para quienes no son especialistas en la materia. Los juristas defienden la naturaleza y las razones que justifican esta forma de estructurar el discurso que tienen que ver con cuestiones de exactitud, la precisión a la hora de dictaminar para que no queden imprecisiones o dudas sobre el mensaje o sentido del texto que se trasmite en una sentencia. Por lo que como afirma Alcaraz Varó (2002) $)^{4}$ se puede decir que es un lenguaje complejo y difícil no solo para los legos en la materia, sino para los mismos estudiosos del derecho.

Desde esta perspectiva de Alcaraz (1994) afirma que "el lenguaje jurídico es un lenguaje que tiene sus raíces en la tradición cultural de cada pueblo". Desde enfoques diferentes como lo es el panorama jurídico, y el lingüístico se suele estudiar con dos miradas distintas,

3 Borja Albi, Anabel. (2000). El texto jurídico inglés y su traducción al español. Barcelona: Ariel Lenguas Modernas.

4 Alcaraz Varó, E., \& Hughes, B. (2002). El español jurídico. Barcelona: Ariel.

5 Alcaraz, Varó, E. (1994). El inglés jurídico: Textos y documentos. Barcelona: Ariel. 
el jurista en su país y en su contexto cultural y profesional del derecho, el lingüista lo hace desde el texto como objeto lingüístico. En ese tenor, es de suma importancia llevar a cabo una aproximación de la producción lingüística en diferentes niveles: el léxico-semántico, morfosintáctico, sociopragmático que involucra el estudio de la naturaleza del discurso jurídico y la apegada al derecho en el sistema que se produce el discurso.

Debido a su carácter específico, el lenguaje jurídico plantea problemas especiales relacionados a la cultura y su reflejo en el lenguaje. Desde una perspectiva lingüístico discursiva se deben reconocer no solo las dificultades que surgen en la transmisión de un mensaje dentro del contexto jurídico; sino que además, han de preocuparse por adentrarse en un sistema lingüístico que en cumpla con los requerimientos de un proceso comunicativo eficaz y su rol en un proceso social.

El tener un conocimiento especializado en esta tipología, no solo atañe al especialista jurídico, sino a quienes trabajan en otras áreas como el lingüista, el traductor, como auxiliar en la aplicación de la justicia en un proceso de peritaje de esta tipología, o áreas más especializadas como la lingüística forense. Para trabajar con los documentos de esta rama del conocimiento, se requiere de conocimientos muy específicos sobre los sistemas legales, y en el caso del lingüista, de los sistemas jurídicos de países con quienes realizarán un proceso como lo es el caso de la traducción, tanto a cuestiones léxico estilísticas como las sociopragmáticas en la traducción de textos jurídicos y culturas del derecho involucradas en este proceso.

\subsection{Pragmática}

Morris $(1985)^{6}$ introdujo el concepto de pragmática para designar la ciencia de los signos en relación con sus intérpretes, que junto a la semántica y la sintaxis formaban una tricotomía, en donde la pragmática permite interpretar el lenguaje en una situación comunicativa concreta. Por lo tanto la pragmática, como disciplina permite considerar los factores extralingüísticos que determinan el uso del lenguaje, es decir los factores que no pueden ser analizados a partir de la gramática, tales como el emisor, destinatario, intención comunicativa, contexto verbal, situación o conocimiento del mundo (Escandell, 1996) ${ }^{7}$.

Así mismo, la pragmática se considera como una disciplina de la lingüística que se encarga de estudiar los fenómenos extralingüísticos que se gestan en los procesos de comunicación en todos los contextos posibles, y es de importancia trascendental para la interpretación del discurso jurídico. A este respecto Escandell (1996), explica su conceptualización de la pragmática como sigue:

se entiende por pragmática el estudio de los principios que regulan el uso del lenguaje en la comunicación, es decir, las condiciones que determinan tanto el empleo de un enunciado concreto por parte de un hablante concreto en una situación comunicativa concreta, como su

6 Morris, C. (1985). Fundamentos de la teoría de los signos. Barcelona: Paidós.

7 Escandell, V. (1996). Introducción a la pragmática. Barcelona, Editorial Ariel, S.A. 
interpretación por parte del destinatario (Escandell, 1996: 13-14).

En el estudio que Escandell (1996) realiza sobre la pragmática, resalta la importancia del análisis y la comprensión de los aspectos que intervienen en una situación comunicativa y que nos permiten comprender situaciones comunicativas de diferente categoría lo que conduce a la comprensión de la producción comunicativa en un discurso de la tipología jurídica.

En el discurso jurídico es de suma importancia comprender estos factores de una manera bastante amplia, puesto que es un discurso extremadamente formal y cortés por provenir de instancias de gobierno o instituciones gubernamentales supeditadas a la ley. El receptor, tiene diversas dimensiones, que va desde el abogado, juez, el demandante, el demandado o el burócrata. Se dice que el discurso jurídico debe presentar sustentos objetivos e imparciales que se reflejan en su objetividad y la búsqueda de la verdad en un proceso legal, por lo que sus conceptos centrales siempre deben ser la equidad y la justicia (Cubells e Iñiguez-Rueda, 2008) ${ }^{8}$.

\subsection{Sociopragmática}

La sociopragmática es una disciplina que estudia la intención comunicativa del hablante para ser asimilada o rechazada por su interlocutor, se interesa por el uso de la lengua

8 Cubells e Iñiguez-Rueda (2008). La construcción de hechos en el discurso jurídico: Análisis del caso de los robos en cajeros automáticos en la ciudad de Barcelona. Revista Española de Investigación Criminológica Artículo 4, Número 6. como un fenómeno real e inmediato con una gran dependencia en el contexto social de una situación dada. Esta disciplina permite analizar la influencia que produce una transferencia de hábitos desde lo social hacia lo lingüístico.

El estudio de un acto comunicativo desde un enfoque socio-pragmático establece una consideración del uso del lenguaje en función de premisas socioculturales que determinan cómo utilizamos el discurso y para qué lo hacemos. Efectivamente, el contexto adquiere relevancia desde esta perspectiva. Para Leech $(1983)^{9}$, la Sociopragmática es una línea de la Pragmática que permite el estudio de las "condiciones más específicas correspondientes a un determinado uso del lenguaje" (p. 54).

La sociopragmática por lo tanto, es una disciplina que estudia el uso de la lengua en su contexto de forma más determinada, teniendo en cuenta los componentes sociales y culturales y está íntimamente ligada a la Pragmática. Baran M. (2010, p. 119) ${ }^{10}$, afirma que la pragmática se ocupa básicamente del estudio de los recursos lingüísticos particulares que proporciona una lengua dada para transmitir los diferentes tipos de actos ilocutivos, y la sociopragmática por su parte, analiza cómo las conceptualizaciones de tipo social o cultural determinan el uso lingüístico.

9 Leech, G. (1983). Principles of Pragmatics. New York: Longman Group Ltda.

10 Baran, M. (2010). Emotividad y convención sociopragmática. Una contribución al estudio del ethos comunicativo de la comunidad hispanohablante peninsular. Polonia: Universidad de Łódź. 
La competencia pragmática según Thomas (1983: 92) ${ }^{11}$, es la habilidad para usar el lenguaje de una forma efectiva para lograr un propósito específico y comprender el lenguaje dentro de un contexto. Por otra parte, Thomas (1983) afirma además, que la socio-pragmática comprende condiciones sociales del lenguaje y de su uso. Para ser competente en cuanto al aspecto socio-pragmático sería, por lo tanto importante saber cuándo y con quién usar adecuadamente un acto de habla, es decir, saber emitir un acto comunicativo en las condiciones apropiadas, por lo que es importante tener conocimiento de reglas tanto sociales como culturales.

En este trabajo se estudian los textos jurídicos, desde la sociopragmática, a partir de un análisis contrastivo para identificar la (des) cortesía e intensificación en un corpus de dos sentencias mexicanas. La competencia pragmática según Thomas (1983: 92) ${ }^{12}$, es la habilidad para usar el lenguaje de una forma efectiva para lograr un propósito específico y comprenderlo dentro de un contexto. Thomas (1983) afirma además que la sociopragmática comprende condiciones sociales del lenguaje y de su uso

La sociopragmática, es la unión de la Pragmática y la Sociolingüística, Saiz Pérez (2004) ${ }^{13}$, afirma que "la competencia sociopragmática

11 Thomas, J. (1983). Cross-cultural pragmatic failure. Applied linguistics, 4 (2), 91-112.

12 Thomas, J. (1983). Cross-cultural pragmatic failure. Applied linguistics, 4 (2), 91-112.

13 Saiz Pérez, I. (2004). La adquisición de la competencia sociopragmática. ¿Son las estancias en el extranjero la clave de su éxito? Tesina, Universidad de Estocolmo. abarca factores extralingüísticos que permiten que la transmisión de un mensaje en el intercambio de un texto oral o escrito sean utilizados de manera adecuada y correcta y suenen lo más natural y nativo posible" (Saiz Pérez, 2004: 2). Así pues, para poder medir y poder diferenciar la competencia sociopragmática de un grupo hay que tener en cuenta la situación intercultural en que se encuentren, ya que personas de diferentes culturas suelen responder, por ejemplo, a un cumplido, sistemáticamente de manera diferente (Spencer-Oatey 2004: 168) $)^{14}$.

Para que un acto de habla sea entendido en su totalidad, es necesario que tanto el emisor como el destinatario sean competentes de la misma legua y tengan cierto nivel de competencia sociopragmática. Esta competencia sociopragmática ha sido abordada por los estudios realizados por Brown y Levinson (1987) ${ }^{15}$, quienes en sus modelos teóricos plantean generalizaciones de cómo funciona la cortesía en los distintos niveles de la lengua, y el concepto de imagen de autonomía y afiliación que ha planteado Bravo $\left(2004^{16}, 2010\right)^{17}$. Por otra parte, para estudiar las estrategias atenuadoras, se utilizan las propuestas de clasificación que plantea Briz (2001) ${ }^{18}$; y las estrate-

14 Spencer-Oatey, H. (2000). Culturally speaking managing rapport in talk across cultures. London: Cassell.

15 Brown \& Levinson (1987). Politeness: Some universals in language usage. Cambridge.

16 Bravo, D. (2004). Actividades de cortesía, imagen social y contextos socioculturales: Una introducción.

17 Bravo, D., Flores N. H., y Cordisco, A. (eds). (2010). Aportes pragmáticas sociopragmáticas y socioculturales de la cortesía en español. Estocolmo / Buenos Aires: Dunken.

18 Briz, A. (2001). El español coloquial en la conversación. 
gias de intensificación se analizan a partir de la clasificación que Martha Albelda (2005) ${ }^{19}$ y Briz $\left(2001^{20}, 2003\right)^{21}$.

A manera de esquema se presenta en la siguiente tabla las categorías sociopragmáticas de la (des)cortesía e intensificación que están presentes en esta tipología discursiva y con las que se realizarán los análisis en el presente trabajo. teóricas de cada una de las categorías sociopragmáticas que claramente se presentan en la tipología discursiva jurídica. Con estas categorías se busca identificar las relaciones y representaciones sociales y culturales en un acto comunicativo de esta naturaleza.

Tabla 1. Clasificación de categorías sociopragmáticas

\begin{tabular}{|c|c|c|c|}
\hline \multicolumn{4}{|c|}{ Categorías sociopragmáticas } \\
\hline Atenuación & $\begin{array}{c}\text { Imagen de autonomía y } \\
\text { afiliación }\end{array}$ & Descortesía & Intensificación \\
\hline $\begin{array}{l}\text { Consiste en minimizar } \\
\text { la fuerza ilocutiva de } \\
\text { los actos del habla y, } \\
\text { con frecuencia, regula } \\
\text { la relación interper- } \\
\text { sonal y social entre } \\
\text { los participantes de } \\
\text { la enunciación. (Briz, } \\
2001,2003 \text { ) }\end{array}$ & $\begin{array}{l}\text { La imagen de autono- } \\
\text { mía (Bravo,2004) } \\
\text { es el concepto que } \\
\text { se refiere a la noción } \\
\text { de independencia y la } \\
\text { libertad de acción del } \\
\text { individuo. La imagen } \\
\text { de afiliación es el de- } \\
\text { seo que permite identi- } \\
\text { ficarse con el grupo. }\end{array}$ & $\begin{array}{l}\text { La descortesía (Kaul } \\
\text { de Marlangeon, 2012) } \\
\text { quiebra el equilibrio } \\
\text { social, no obstante, } \\
\text { es un comportamiento } \\
\text { apropiado a un desig- } \\
\text { nio comunicativo, es } \\
\text { ocasional, personal y } \\
\text { ad hoc. }\end{array}$ & $\begin{array}{l}\text { Albelda (2005) y Briz } \\
\text { (2001), sitúan la inten- } \\
\text { sificación como una } \\
\text { función que permite } \\
\text { hacer que algo tenga } \\
\text { mayor intensidad para } \\
\text { persuadir y conven- } \\
\text { cer al interlocutor. }\end{array}$ \\
\hline
\end{tabular}

En el siguiente apartado se presenta de manera detallada y con las consideraciones

Esbozo de pragmagramática. Editorial Ariel. 2a Edición. Barcelona España.

19 Albelda M. (2005). La intensificación en el español coloquial. Universidad de Valencia.

20 Briz, A. (2001). El español coloquial en la conversación. Esbozo de pragmagramática. Editorial Ariel. 2a Edición. Barcelona España.

21 Briz Gómez, Antonio (2003). La estrategia atenuadora en la conversación cotidiana española, en D. Bravo (ed.) (2003a), pp. 17 - 46.

\subsection{Categorías sociopragmáticas}

\subsubsection{Atenuación}

Para lograr una clara comprensión de los conceptos de la atenuación y cortesía, se define, en primera instancia, el recurso de la atenuación, el cual de acuerdo con diversos autores es una categoría pragmática cuya función consiste en minimizar la fuerza ilocutiva de los actos de habla y, con frecuencia, regula la relación interpersonal y social entre los participantes de la enunciación. Se emplea a través 
de una serie de estrategias pragmalingüísticas para lograr las metas deseadas en la comunicación (Briz, 2003²2, 2007²3).

A. Briz (199524:103-122) enumera siete funciones prototípicas para la aparición de la atenuación; estas serían: minimizar el autoelogio, maximizar el elogio, suavizar una posición de conflicto entre interlocutores, relativizar juicios u opiniones del hablante, minimizar la acción del emisor, en los actos ilocutivos de petición y para suavizar el contenido del mensaje cuando este puede representar una amenaza para la imagen del interlocutor.

De acuerdo con Briz (2003), las características pragmalingüísticas de la atenuación, esta busca a nivel lingüístico llegar a un acuerdo en la conversación, a través del empleo de estrategias de minimización, en donde el hablante y oyente llegan a una negociación.

Estas funciones de atenuación, claramente se presentan en el discurso jurídico, puesto a como se define el proceso de sentencia es aquel en el que uno de los actores se ve perjudicado ante una situación de la que se deriva la demanda y otra parte la que produce el prejuicio o daño, entonces los recursos que utilizan los involucrados buscan suavizar la si-

22 Briz Gómez, Antonio (2003). La estrategia atenuadora en la conversación cotidiana española, en D. Bravo (ed.) (2003a), pp. 17 - 46.

23 Briz Gómez, Antonio. (2007). Para un análisis semántico, progmático y sociopragmático de la cortesía atenuadora en España y América. Lingüística Española Actual XXIX/1.

24 Briz Gómez, Antonio. (1995). La conversación coloquial. Anejo XVI de la revista Cuadernos de Filología. Universidad de Valencia. tuación de conflicto entre los interlocutores y establecer una solución al conflicto derivado de la demanda.

En las sentencias analizadas se puede observar cómo los involucrados hacen uso constante de un lenguaje cortésmente atenuado que les permite proteger su imagen a través del uso de fórmulas corteses y el uso de estrategias que mitigan la fuerza ilocutiva que representa un proceso de demanda, en este caso de carácter civil.

\subsubsection{Cortesía}

Por otra parte el recurrir a la cortesía, según Brown y Levinson (1987) ${ }^{25}$, se debe a la necesidad de facilitar las relaciones sociales y como una manera de compensar la agresividad o amenaza a la imagen de los participantes en la interacción. En la base de su doctrina se encuentran dos supuestos: por un lado, la concepción de que existe un potencial de enfrentamiento, una lucha de tensiones entre los participantes de la comunicación; por otro lado, la consideración de que es deseable para todos ellos evitar o subsanar dicho enfrentamiento y lograr una cierta armonía.

La relación que se establece entre la atenuación y cortesía consecuente de un discurso jurídico se debe a la naturaleza de dicha tipología, al que algunos estudiosos del tema citan como característica distintiva del lenguaje legal; su complejidad no proviene sólo de su estructura sintáctica, sino que es consecuencia de los aspectos pragmáticos que lo

25 Brown \& Levinson (1987). Politeness: Some universals in language usage. Cambridge. 
contextualizan. Los textos jurídicos muestran rasgos característicos muy específicos: un lenguaje especializado, fosilizado y con estructuras textuales estereotipadas (Borja Albi, $2000)^{26}$. El discurso jurídico se caracteriza típicamente como formal e incluso hiperformal, y tanto la formalidad y las características antes mencionadas, permiten categorizarlo como un discurso en el que se presenta la cortesía protocolaria, a la cual diversos estudiosos de la pragmática y la cortesía en específico se refieren como un registro formal, posiblemente Institucional, en donde existe un conjunto de reglas de trato interpersonal, que han sido previamente establecidas.

La cortesía en el ámbito discursivo pretende conseguir la colaboración de los interlocutores y el desarrollo armónico, sin tensiones de la conversación (Briz, 2003) ${ }^{27}$. Puede tratarse de una cortesía normativa, que se deriva de una norma social de comportamiento, como en saludos, despedidas, agradecimientos; o de una cortesía estratégica, que los hablantes emplean para asegurarse del logro de algún objetivo, en la realización cortés de una petición.

\subsubsection{Conceptos de Imagen y afiliación}

En cuanto a los conceptos de imagen Diana Bravo (1999) ${ }^{28}$ propone como alternativas de

26 Borja Albi, Anabel. (2000). El texto jurídico inglés y su traducción al español. Barcelona: Ariel Lenguas Modernas

27 Briz Gómez, Antonio (2003). La estrategia atenuadora en la conversación cotidiana española, en D. Bravo (ed.) (2003a), pp. 17 - 46

28 Bravo, D. (1999). ¿Imagen 'positiva' vs imagen 'negativa'?: Pragmatica sociocultural y componentes de face. Oralia. Analisis del Discurso Oral. la imagen positiva y negativa de las teorías de Brown y Levinson, (1987) ${ }^{29}$ las necesidades de autonomía y afiliación en las relaciones humanas. Define a la imagen de autonomía como el concepto mediante el cual un integrante de un grupo adquiere un contorno propio dentro del mismo, se refiere principalmente a la noción de independencia y la libertad de acción del individuo. La imagen de afiliación es el deseo de imagen que permite identificarse con el grupo y depende de cada cultura según su idiosincrasia.

Bravo (2004) $)^{30}$, agrega además que no toda presentación de una imagen de sí mismo o del grupo al cual se pertenece se realiza dentro de la dimensión de la cortesía. Cuando alguien afirma ser una persona sincera, no se realiza una actividad de cortesía, pero si una de imagen, por lo que aunque se dice que las actividades de cortesía son actividades de imagen, ya que esta siempre es una estrategia para quedar bien con el otro, no siempre las actividades de imagen son de cortesía (Flores Hernández, 2002) ${ }^{31}$.

\subsection{Descortesía}

La descortesía indica Kaul de Marlangeon

29 Brown \& Levinson (1987). Politeness: Some universals in language usage. Cambridge.

30 Bravo, D. (2004). Actividades de cortesía, imagen social y contextos socioculturales: Una introducción. Actas del Primer Coloquio del programa EDICE. Estocolmo: Programa EDICE. 31 Flores Hernández, N. (2002). La cortesia en la conversación Española de familiares y amigos: La búsqueda de equilibrio entre la imagen del hablante y la imagen del destinatario. Programa EDICE. 
$(2012)^{32}$ quiebra el equilibrio social, no obstante es un comportamiento apropiado a un designio comunicativo, es ocasional, personal y ad hoc, y como característica en el caso de la demanda de adopción plena, al describir los demandantes el comportamiento del juez a juicio de los demandantes se considera una ofensa voluntaria hacia el juez para defender su imagen y dañar la del juez. Kaul de Marlangeon (2005) ${ }^{33}$ reconoce dos actitudes humanas fundamentales para la descortesía de fustigación, las de refractariedad y de afiliación exacerbada, que claramente se manifiestan en los ejemplos de descortesía en la sentencia de adopción.

En cuanto a la descortesía en el discurso jurídico, autores como Bernal (2010) ${ }^{34}$ y Archer $(2011)^{35}$, solo por mencionar algunos, han estudiado la forma en que los juristas utilizan

32 Kaul de Marlangeon, S. (2012). Encuadre de aspectos teórico-metodológicos de la descortesía verbal en español. Miradas multidisciplinares de los fenómenos de cortesía y descortesía en el mundo hispánico, en Escamilla Morales J. y Vega G. H. (eds.) Universidad del Atlantico y programa EDICE, 76.

33 Kaul de Marlangeon, S.(2005). Descortesía de fustigación por afiliación exacerbada o refractariedad. En D. Bravo (Ed.), Estudios de la (des) cortesía en español. Categorías conceptuales y aplicaciones a corporas orales y escritos. Vol I, pp 299-318). Buenos Aires: Programa EDICE- Dunken.

34 Bernal, M. (2010). Descortesía en el contexto judicial. El caso del juicio del 11-M. En F. Orletti y L. Mariottini (Eds.), (Des) cortesía en español. Espacios teóricos y metodológicos para su estudio (pp. 599-636). Roma-Estocolmo: Università degli Studi Roma Tre-EDICE.

35 Archer, D. (2011). Facework and im/politeness across legal contexts: An introduction. Journal of Politeness Research, n. 7, p. 1-19, 2011. atenuaciones de este tipo en la interacción con los involucrados en las sentencias, ya sean expertos o no, Bernal ( 2010) al citar a Kryk-Kastovsky (2006) $)^{36}$ hace destacar que la forma de comunicación en un juicio o proceso legal se ha venido asociando más bien a comportamientos de cortesía, dadas las convenciones del registro formal, sin embargo, es importante destacar que la descortesía no está ausente en dicho registro. La descortesía agrega, ha sido vista durante bastante tiempo como subordinada a la cortesía, sin embargo, Lachenicht $(1980)^{37}$ proporcionó una rápida respuesta al modelo de cortesía postulado por Brown y Levinson (1987) $)^{38}$ al presentar un modelo de descortesía.

Bernal (2010) $)^{39}$ hace una propuesta de la descortesía a partir de un análisis llevado a cabo en conversaciones informales:

a) La descortesía normativa que entre personas allegadas cumple con las expectativas de la situación de riña donde se producen actos potencialmente amenazantes, como hacer reproches o criticar, etc.

36 Kryk-kastovsky, B. (2006) Impoliteness in early modern in English courtroom discourse. Journal of Historical Prgamatic. John Benjamins.

37 Lachenicht L. G. (1980). Aggravating language: A study of abusive and insulting language. Paper in Linguistics.

38 Brown \& Levinson (1987). Politeness: Some universals in language usage. Cambridge.

39 Bernal, M. (2010). Descortesía en el contexto judicial. El caso del juicio del 11-M. En F. Orletti y L. Mariottini (Eds.), (Des) cortesía en español. Espacios teóricos y metodológicos para su estudio (pp. 599-636). Roma-Estocolmo: Università degli Studi Roma Tre-EDICE. 
b) La descortesía producida por amenazas ni atenuadas ni reparadas a la imagen del interlocutor, ya sea de su imagen personal, su imagen de rol, o la imagen dentro de un grupo determinado, o del interlocutor en relación con su familia, amigos $u$ otro grupo al que pertenece.

c) La descortesía por incumplimiento de las normas de cortesía, que para la situación de encuentros entre familiares y amigos abarca los actos de romper expectativas del ritual de cortesía en la situación de encuentro.

Kaul de Marlangeon (2012) $)^{40}$ afirma que mientras la cortesía, como principio regulador de la conducta, facilita el equilibrio social en la convivencia, la descortesía procura el efecto contrario, de quebrar ese equilibrio.

\subsection{Intensificación}

Albelda (2005) $)^{41}$ y Briz (2001) ${ }^{42}$, sitúan a la intensificación como una función que permite hacer que algo tenga mayor intensidad para conseguir persuadir y convencer al interlocutor. La intensificación considera Albelda

40 Kaul de Marlangeon, S. (2012). Encuadre de aspectos teórico-metodológicos de la descortesía verbal en español. Miradas multidisciplinares de los fenómenos de cortesía y descortesía en el mundo hispánico, en Escamilla Morales J. y Vega G. H. (eds.) Universidad del Atlantico y programa EDICE, 76.

41 Albelda M. (2005). La intensificación en el español coloquial. Universidad de Valencia.

42 Briz, A. (2001). El español coloquial en la conversación. Esbozo de pragmagramática. Editorial Ariel. 2a Edición. Barcelona España.
$(2005)^{43}$, se presenta con mayor frecuencia en la comunicación escrita, puesto que quien emite el mensaje debe valerse con mayor intensidad de estrategias comunicativas como la atenuación y la intensificación para lograr conseguir su propósito.

Según la definición de Briz (1995a:53) intensificación es una "estrategia conversacional retórica para dar a entender más de lo que realmente se dice, de manipular realzando los enunciados con finalidades diferentes". Siguiendo de nuevo a Briz (1995:22-30), las funciones en las que suele aparecer la intensificación serían principalmente cuatro: expresar cantidad y/o cualidad, reforzar o manipular la actitud del hablante, enfatizar el acuerdo o el desacuerdo e intensificar una acción.

En este sentido Albelda por su parte (2005, 61-62) propone una clasificación de los recursos intensificadores a nivel del enunciado y de la enunciación, de la que se pueden extraer una serie de estrategias, de las cuales se hace uso a menudo en el acto comunicativo:

1. Recursos morfemáticos: Están entre esta categoría gramatical los sufijos y prefijos, en el uso de la lengua oral y escrita a menudo se hace uso de afijos que permiten que ciertas expresiones tengan carácter intensificador.

2. Recursos léxicos: Se encuentran dentro de esta categoría gramatical las unidades

43 Albelda M. (2005). La intensificación en el español coloquial. Universidad de Valencia.

44 Briz Gómez, Antonio. (1995). La conversación coloquial. Anejo XVI de la revista Cuadernos de Filología. Universidad de Valencia. 
simples, es decir, los sustantivos, adjetivos, verbos, adverbios, así como también las fraseologías, locuciones, refranes y formas rutinarias.

3. Recurso sintácticos: Entre los recursos: Entre los recursos sintácticos encontramos los modificadores de las categorías gramaticales nucleares, las estructuras sintácticas intensificadas en sí mismas, las repeticiones y las enumeraciones. A nivel de los recursos sintácticos, la estructura más común y frecuentemente hallada en las frases intensificadas es: "muy+adjetivo/adverbio" y "mucho+sustantivo", Albelda $(2005,91)^{45}$.

4. Recursos semánticos: Es una de las categorías que engloban quizás los recursos más utilizados por el ser humano en la emisión de mensajes. Encontramos en esta categoría el uso de tropos y la ironía, elementos que se emplean en la comunicación con el fin de reforzar el enunciado emitido.

\section{METODLOGÍA DE ANÁLISIS DE SENTENCIA}

Este trabajo busca presentar aspectos fundamentales en los estudios del discurso jurídico mexicano para identificar las estrategias de (des)cortesía e intensificación comunes en esta tipología discursiva. Todos los antecedentes en el presente trabajo se analizan con una metodología cualitativa; a partir de la observación de ejemplos que se extraen de textos emitidos de una manera auténtica y desde un enfoque sociopragmático del análisis de sentencias.

45 Albelda M. (2005). La intensificación en el español coloquial. Universidad de Valencia.
El corpus que se analiza en este trabajo consiste en el análisis de dos sentencias civiles emitidas en juzgados civiles del estado de Nuevo León, México: una sentencia de adopción plena y una sentencia de divorcio. Debido a la extensión de las sentencias solo se analiza la parte introductoria y la argumentación de la apelación por los demandantes de la sentencia de adopción. En la sentencia de divorcio presentaremos los considerandos o puntos resolutivos de la sentencia de divorcio.

\subsection{Atenuación}

Con esta estrategia de la atenuación se busca mitigar la fuerza elocutiva de un acto, encontrándose que éste puede ser de tipo asertivo o exhortativo, donde se mitiga la actuación del yo y/o tu Briz (2001)46. A. Briz (1995:103-122) ${ }^{47}$ enumera siete funciones prototípicas para la aparición de la atenuación; estas serían: minimizar el autoelogio, maximizar el elogio, suavizar una posición de conflicto entre interlocutores, relativizar juicios $u$ opiniones del hablante, minimizar la acción del emisor en los actos ilocutivos de petición y para suavizar el contenido del mensaje cuando este puede representar una amenaza para la imagen del interlocutor. Como vemos, todas ellas coinciden en la idea de una cierta sumisión por parte del emisor y una exaltación o relace del receptor del mensaje tratando siempre de evitar

46 Briz, A. (2001). El español coloquial en la conversación. Esbozo de pragmagramática. Editorial Ariel. 2a Edición. Barcelona España.

47 Briz Gómez, Antonio. (1995). La conversación coloquial. Anejo XVI de la revista Cuadernos de Filología. Universidad de Valencia. 
el conflicto, ya sea por oposición de opiniones o porque la imagen del receptor pueda resultar dañada.

\subsubsection{Atenuación con cortesía}

En cuanto a la atenuación con efecto de cortesía, es una estrategia que busca cierto equili- cias de divorcio y adopción encontramos está forma de atenuación en las que se observa este tipo de estrategia comunicativa.

Con estos ejemplos se muestra la representación de la atenuación en la que se busca suavizar una posición de conflicto entre interlocutores, ya sea con la impersonalización u

\section{Tabla 2. Ejemplo de atenuación con cortesía en Sentencias civiles} (Selección propia de la autora)

\begin{tabular}{|l|l|}
\hline \multicolumn{1}{|c|}{$\begin{array}{c}\text { Sentencias de divorcio necesario y } \\
\text { adopción plena }\end{array}$} & $\begin{array}{c}\text { Táctica lingüística de atenuación/cortesía (procedi- } \\
\text { miento) }\end{array}$ \\
\hline el juez tercero (...) pronunció & $\begin{array}{l}\text { Sin pronombre en español para mitigar la actuación del } \\
\text { yo. }\end{array}$ \\
\hline y se lo expusimos al juzgador de origen & Uso de la impersonalización con el reflexivo se y lo. \\
\hline se lo expusimos al Juzgador. & Uso de la impersonalización con el reflexivo se y lo. \\
\hline $\begin{array}{l}\text { Se desecha la solicitud planteada de los } \\
\text { suscritos ordenando el archivo y la baja } \\
\text { del expediente }\end{array}$ & $\begin{array}{l}\text { Impersonalización del yo con el uso del reflexivo, /se } \\
\text { desecha/ en el cual se impersonaliza también la acción } \\
\text { realizada al utilizar el concepto /los suscritos/ }\end{array}$ \\
\hline $\begin{array}{l}\text { Circunstancias que este H Tribunal de } \\
\text { Alzada deberá de considerar }\end{array}$ & $\begin{array}{l}\text { Se considera al colectivo H. Tribunal para evitar el uso } \\
\text { del yo.. }\end{array}$ \\
\hline $\begin{array}{l}\text { se supla la deficiencia de la queja en la } \\
\text { exposición de los presentes agravios en } \\
\text { beneficio de los suscritos y del menor }\end{array}$ & $\begin{array}{l}\text { Los suscritos impersonaliza a los involucrados se man- } \\
\text { tiene la atenuación e impersonalización de los actores } \\
\text { en el proceso de la sentencia. }\end{array}$ \\
\hline
\end{tabular}

Fuente: Elaboración propia obtenida del análisis de revisión documentaria.

brio y protección de la imagen del yo y tú, son construcciones que esconden el agente de la acción (Briz Gómez, 2012) ${ }^{48}$. En las senten-

48 Briz Gómez A. (2012). La (no) atenuación y la (des)cortesía, lo lingüístico y social: ¿son pareja? En J. Escamilla Morales y G. H. Vega (Eds.), Miradas Multidisciplinarias a los fenómenos de cortesía y descortesía en el mundo hispánico. Barranquilla/Estocolmo: CADIS-Programa EDICE. otros recursos como la sustantivación en el caso del término los suscritos o minimizar la acción del emisor, en este caso el juez, en los actos ilocutivos de petición y para suavizar el contenido del mensaje cuando este puede representar una amenaza para la imagen del interlocutor. 


\subsubsection{Atenuación sin efectos de cortesía}

Briz Gómez (2012) ${ }^{49}$ define la atenuación como "un mecanismo lingüístico que tiene que ver siempre con la eficacia y la actividad argumentativa y no siempre con la cortesía". La atenuación por lo tanto se logra con la despersonalización del yo con la cual se evita la responsabilidad sobre lo dicho, se atenúa con el propósito de se acepten las demandas, pero no de manera cortés.

\subsubsection{Análisis de imagen de autonomía e imagen de afiliación}

En cuanto a los conceptos de imagen, Diana Bravo (1999), ${ }^{50}$ propone como alternativas de la imagen positiva y negativa de las teorías de Brown y Levinson, (1987) $)^{51}$, las necesidades de autonomía y afiliación en las relaciones humanas. La autora define a la imagen de autonomía como el concepto mediante el cual un integrante de un grupo adquiere un contorno propio dentro

\section{Tabla 3. Ejemplo de atenuación sin cortesía en Sentencias civiles} (Selección propia de la autora)

\begin{tabular}{|l|l|}
\hline \multicolumn{1}{|c|}{$\begin{array}{c}\text { Sentencias de adopción plena y divorcio } \\
\text { necesario }\end{array}$} & \multicolumn{1}{c|}{$\begin{array}{c}\text { Táctica lingüística de atenuación/cortesía } \\
\text { (procedimiento) }\end{array}$} \\
\hline $\begin{array}{l}\text { dado que el legislador en dicho numeral estable- } \\
\text { ce que se debe velar por el interés superior de } \\
\text { los menores (...) fue omiso en considerar dicha } \\
\text { determinación. }\end{array}$ & $\begin{array}{l}\text { Se evita la responsabilidad del legislador y se } \\
\text { atenúa con la perífrasis verbal fue omiso pero no } \\
\text { es cortés. }\end{array}$ \\
\hline $\begin{array}{l}\text { Con lo anterior se da por terminado este } \\
\text { convenio firmándolo de conformidad los pro- } \\
\text { moventes y obligándose a pasar por él en todo } \\
\text { tiempo y lugar como asunto resuelto. }\end{array}$ & $\begin{array}{l}\text { Se aceptan las demandas, pero la cortesía está } \\
\text { disminuida... }\end{array}$ \\
\hline $\begin{array}{l}\text { es evidente la violación que realiza el juzgador } \\
\text { en perjuicio de los suscritos y del menor }\end{array}$ & $\begin{array}{l}\text { Es evidente la violación/ en perjuicio de los sus- } \\
\text { critos Se aceptan las demandas, pero la cortesía } \\
\text { está disminuida. es como lo marca Briz, un ate- } \\
\text { nuación dialógica cuando existe un desacuerdo o } \\
\text { disconformidad con respecto a la intervención del } \\
\text { otro interlocutor (Briz, 2001) }\end{array}$ \\
\hline
\end{tabular}

Fuente: Elaboración propia obtenida del análisis de revisión documentaria.

49 Briz Gómez A. (2012). La (no) atenuación y la (des)cortesía, lo lingüístico y social: ¿son pareja? En J. Escamilla Morales y G. H. Vega (Eds.), Miradas Multidisciplinarias a los fenómenos de cortesía y descortesía en el mundo hispánico. Barranquilla/Estocolmo: CADIS-Programa EDICE.
50 Bravo, D. (1999). ¿Imagen 'positiva' vs imagen 'negativa'?: Pragmatica sociocultural y componentes de face. Oralia. Analisis del Discurso Oral.

51 Brown \& Levinson (1987). Politeness: Some universals in language usage. Cambridge. 
del mismo, se refiere principalmente a la noción de independencia y la libertad de acción del individuo. La imagen de afiliación es el deseo de imagen que permite identificarse con el grupo y depende de cada cultura según su idiosincrasia. En este trabajo se considera la afiliación que se crea en el grupo que determinan los abogados, jueces o incluso los comparecientes en el proceso de litigio. afiliación puede ocurrir entre los grupos de un cierto gremio o en este caso a las mismas leyes o códigos.

\subsection{Descortesía}

Fuentes $(2011)^{52}$, afirma que la descortesía en el discurso se utiliza de una manera consciente con una función argumentativa para así

Tabla 4. Ejemplos de imagen de autonomía en Sentencia de Adopción (Selección propia de la autora)

\section{Sentencia de adopción}

Los apelantes ciudadanos $\mathrm{XX}$ y XX, comparecieron expresando los agravios de su intención por escrito

Fuente: Elaboración propia obtenida del análisis de revisión documentaria.

En este ejemplo son los promoventes de la sentencia de adopción quienes, bajo su propia decisión, comparecen ante la autoridad para manifestar su solicitud de atender a sus demandas ante un juicio que consideran no justo para sus fines, que en este caso es la adopción de un menor. ayudar al hablante a conseguir sus objetivos comunicativos. Ya quedará a elección del hablante decidir si desea emplear la cortesía o descortesía, por lo que para ello es importante que considere cuál es su intención comunicativa, sus objetivos y el fin argumentativo, así como también los aspectos sociales que ro-

\section{Tabla 5. Ejemplos imagen de afiliación en Sentencia de Divorcio} (Selección propia de la autora)

\begin{tabular}{|l|}
\hline \multicolumn{1}{|c|}{ Análisis en Sentencia de divorcio } \\
\hline $\begin{array}{l}\text { SEGUNDO: Asimismo, la competencia de este órgano jurisdiccional para conocer de la demanda de } \\
\text { divorcio intentada, se surte de conformidad con lo establecido en los artículos } 98,99,100,111\end{array}$ \\
\hline
\end{tabular}

Fuente: Elaboración propia obtenida del análisis de revisión documentaria.

En este último ejemplo se muestra la afiliación del órgano jurisdiccional se afilia a los códigos que sustentan la decisión tomada para la resolución en la sentencia de divorcio. La
52 Fuentes, C. (2011). (Des)cortesía y violencia verbal: implicaciones lingüísticas y sociales. Aproximaciones a la (des) cortesía verbal en español. E. R. A. Lara, \& E. B. Peña (Eds.). Peter Lang. 27-64. 
dean al tipo de discurso y las características personales. Es así pues que la cortesía no es lo "bueno" y la descortesía lo "malo" sino que ambos son estrategias del discurso que los hablantes emplean y que les ayudan a alcanzar sus objetivos.

Como parte de su estudio a la descortesía, Silvia Kaul (2012) ${ }^{53}$, reconoce los diferentes tipos que existen y las clasifica en una escala en la que la descortesía de fustigación es la que mayor daño genera hacia la imagen de a quien
Esta descortesía de fustigación se realiza mediante el uso de actos directos con la intención de que las palabras del hablante agredan al oyente y lo inciten a la confrontación o desafío. Este tipo de descortesía se caracteriza por mostrar comportamientos volitivos, conscientes y estratégicos. Por este motivo, Silvia Kaul (2012), compara la descortesía de fustigación con el sentido metafórico de "dar azotes", y menciona que la violencia que ejerce de forma verbal puede presentarse en diferentes niveles de intensidad y dejarse ver como ira o

Tabla 6. Ejemplo de descortesía en Sentencia de Adopción

(Selección propia de la autora)

\begin{tabular}{|c|}
\hline Sentencia de adopción \\
\hline $\begin{array}{l}\text { Los apelantes ciudadanos __ y comparecieron expresando los agravios de su } \\
\text { intención por escrito presentado ante el juzgado de origen en fecha } 30 \text { de octubre de } 2013 \text {, mismos } \\
\text { que se interpusieron al tenor siguiente: } \\
\text { Nos causa Agravios el auto de fecha 23- veintitrés de octubre del presente año, auto en el que, del } \\
\text { juez inferior de una manera arbitraria, ilegal, contraria a derecho, mezquina, cruenta y fuera } \\
\text { de toda consideración humana al indebidamente desechar la solicitud del Procedimiento Oral de } \\
\text { Jurisdicción Voluntaria sobre ADOPCIÓN respecto al menor. }\end{array}$ \\
\hline
\end{tabular}

Fuente: Elaboración propia obtenida del análisis de revisión documentaria.

vaya dirigida, mientras que los que se encuentran en la escala con menor intensidad son los actos descorteses con intencionalidad cortés.

53 Kaul de Marlangeon, S. (2012). Encuadre de aspectos teórico-metodológicos de la descortesía verbal en español. Miradas multidisciplinares de los fenómenos de cortesía y descortesía en el mundo hispánico, en Escamilla Morales J. y Vega G. H. (eds.) Universidad del Atlantico y programa EDICE, 76 . cólera, dada la estrecha relación que este tipo de actos mantiene con las emociones.

Como se observa en el ejemplo anterior, el quiebre de la comunicación cortés al considerar 'inaceptable' la forma de actuar del juez ante las demandas solicitadas, busca desacreditar el actuar en su resolución y lograr el 
objetivo deseado. Como afirma Kaul (2012) ${ }^{54}$ estas estrategias del discurso que los hablantes emplean les ayudan a alcanzar sus objetivos en su proceso legal.

\subsection{Intensificación}

En lo que respecta al fenómeno de la intensificación, se pudo apreciar que la intensificación en su tesis doctoral La intensificación en el español coloquial, donde propone un esquema de clasificación sobre las estrategias y formas de intensificación presentes en el español (cf. pág. 14-17). Los resultados que se obtuvieron en cuanto a estrategias intensificadoras se pueden expresar a través de la siguiente clasificación y ejemplificación:

Tabla 7. Intensificación con sustantivo

(Selección propia de la autora)

\begin{tabular}{|l|}
\hline \multicolumn{1}{|c|}{ Sentencia de adopción } \\
\hline $\begin{array}{l}\text { Los apelantes ciudadanos ___ } \\
\text { por escrito }\end{array}$ \\
\hline
\end{tabular}

Fuente: Elaboración propia obtenida del análisis de revisión documentaria.

se manifiesta más claramente en el texto de La estrategia se manifiesta en el mismo conadopción plena. Para dicho análisis se partió cepto de la manifestación del concepto los del planteamiento que hace Albelda (2005) $)^{55}$ agravios que también representa una forma

Tabla 8. Intensificación con adjetivos

(Selección propia de la autora)

\section{Sentencia de adopción}

en el que del juez inferior de una manera arbitraria, ilegal, contraria a derecho, mezquina, cruenta y fuera de toda consideración humana

Fuente: Elaboración propia obtenida del análisis de revisión documentaria.

54 Kaul de Marlangeon, S. (2012). Encuadre de aspectos teórico-metodológicos de la descortesía verbal en español. Miradas multidisciplinares de los fenómenos de cortesía y descortesía en el mundo hispánico, en Escamilla Morales J. y Vega G. H. (eds.) Universidad del Atlantico y programa EDICE, 76 .

55 Albelda M. (2005). La intensificación en el español coloquial. Universidad de Valencia. intensificar el actuar del juez en prejuicio de sus demandas para lograr hacer que sus demandas tengan una mayor intensidad para conseguir persuadir y convencer al interlocutor.

El valor intensificador trasmite las categorías gramaticales del uso de este recurso a los ad- 
jetivos, con los conceptos de manera arbitraria, ilegal, mezquina, cruenta lo que maximiza la intención de la toma de decisión del juez. Se presenta además el recurso fraseológico o unidades complejas /fuera de toda consideración humana/.

Tabla 9. Intensificación con adverbio (Selección propia de la autora) TEXTO ORIGEN

El juez al indebidamente desechar la solicitud de los suscritos

Fuente: Elaboración propia obtenida del análisis de revisión documentaria.

La intensificación es a través del recurso sin- En el análisis previo de las sentencias de táctico del adverbio /indebidamente/ que mo- adopción y divorcio, se observan los recursos difica o intensifica la acción del verbo. de intensificación de derivación morfológica,

Tabla 10. Intensificación con adjetivo y sustantivos (Selección propia de la autora) TEXTO ORIGEN

El juez al manifestar actos de Autoridad que se traducen en la inevitable violación y vulneración en perjuicio de los suscritos comparecientes y del menor XX.

Fuente: Elaboración propia obtenida del análisis de revisión documentaria.

La intensificación se da en dos sentidos a tra- que son muy productivos en la expresión de vés del recurso léxico del adjetivo que modifi- este recurso. Estos intensificadores se proca a dos sustantivos, que también son inten- yectan o se forman a partir de las cuatro casificadores /inevitable violación y vulneración/. tegorías gramaticales que admiten matización

Tabla 11. Intensificación con adjetivo, sustantivo y verbo (Selección propia de la autora)

\section{TEXTO ORIGEN}

El juez al manifestar Sin embargo, de una manera ilegal, arbitraria y cruenta, el Ad-quo desecha el presente procedimiento sin considerar que los suscritos hemos cumplimentando con todos y cada uno de los requisitos legales más elementales y esenciales del Juicio de Adopción,

Fuente: Elaboración propia obtenida del análisis de revisión documentaria. 
gradual de intensidad significativa: sustantivos, verbos, adjetivos y adverbios (Vigara 1992: 146). ${ }^{56}$

\section{RESULTADOS}

En cuanto a los estudios pragmáticos aplicados al ámbito jurídico, por una parte, tanto jueces como fiscales, abogados y demás juristas, podrían discernir con mayor facilidad las intenciones de los involucrados en un proceso, o si estos desvían su discurso para conseguir un objetivo determinado, y, por otra parte, crear conciencia del cumplimiento de las máximas en un acto del habla por parte de los juristas. Se afirma que es necesario generar una conciencia sobre el uso del lenguaje en este contexto, en todos los aspectos, cómo se emite un juicio, el rol del emisor y del receptor en un proceso jurídico, y las intenciones de los involucrados. Se debe observar como un discurso en el que, para lograr su objetivo, que es el cumplimiento cabal de la ley, se consideran todo tipo de interpretaciones, que estas interfieren en el adecuado desarrollo de los procesos jurídicos.

$Y$ esto es de gran trascendencia en el cumplimiento del fallo en una sentencia, pues como afirma Borja (2000) ${ }^{57}$, es un texto emitido por quien imparte la justicia y los receptores son los ciudadanos, o la administración de la justicia, y su finalidad, afirma, debe constituirse como una comunicación entre ambos, y como un discurso que regula las relaciones sociales

56 Vigara Tauste, Ana María (1992). Morfosintaxis del español coloquial (Esbozo estilístico). Madrid, Gredos.

57 Borja Albi, Anabel. (2000). El texto jurídico inglés y su traducción al español. Barcelona: Ariel Lenguas Modernas. de los particulares con los órganos judiciales. Por un lado, y como se encontró en los códigos naturales del discurso jurídico, por el rol que juegan las instituciones y la envestidura que representan las personas que emiten una resolución en una sentencia, los textos que aquí se analizan, muestran las estrategias de cortesía (Bernal, 2010) ${ }^{58}$ e imagen (Bravo 2004) $)^{59}$ derivados de su naturaleza, y en menor grado, las estrategias de descortesía. Como bien afirma Bernal (2010), ${ }^{60}$ los textos legales son eminentemente corteses por los órganos que los emiten. Por otro lado, tanto los jueces, como las partes involucradas en un proceso legal, por lo general, se expresan en sus declaraciones, en forma de impersonalización, y se esconde el agente de la acción, como manera de proteger su imagen.

El jurista, en el español mexicano, se expresa en nombre de las instituciones y no de manera personal, usan frases donde indican que las resoluciones son emitidas en conformidad con lo que establecen los Códigos Civiles, en este caso. El jurista nunca se expresa en primera persona para tomar decisiones du-

58 Bernal, M. (2010). Descortesía en el contexto judicial. El caso del juicio del 11-M. En F. Orletti y L. Mariottini (Eds.), (Des) cortesía en español. Espacios teóricos y metodológicos para su estudio (pp. 599-636). Roma-Estocolmo: Università degli Studi Roma Tre-EDICE.

59 Bravo, D. (2004). Actividades de cortesía, imagen social y contextos socioculturales: Una introducción. Actas del Primer Coloquio del programa EDICE. Estocolmo: Programa EDICE. 60 Bernal, M. (2010). Descortesía en el contexto judicial. El caso del juicio del 11-M. En F. Orletti y L. Mariottini (Eds.), (Des) cortesía en español. Espacios teóricos y metodológicos para su estudio (pp. 599-636). Roma-Estocolmo: Università degli Studi Roma Tre-EDICE. 
rante un proceso de sentencia, ni para emitir las partes resolutivas o los fallos, el juez sólo toma el rol de emitir juicios para que se ejerza la institucionalidad de las leyes y para que éstas se cumplan.

La imagen de afiliación está presente, al ser los abogados parte de un gremio, y se afilian a las formas y estructuras del grupo de profesionistas de este ramo, y la cortesía normativa, además de ser recurrente en el discurso jurídico, permite identificar y familiarizarse con formulismos que son característica de esta tipología. Debido a que el discurso jurídico posee una estructura que no sólo se apega a su lengua, sino a una cultura con representación de los códigos del Derecho, se deben atender las propiedades no sólo léxicas, sintácticas, semánticas, sino las pragmáticas y sociopragmáticas del signo como la (des)cortesía e intensificación que atañen al discurso jurídico.

\section{CONCLUSIÓN}

El análisis del discurso jurídico desde la perspectiva pragmática permite observar y comprender la manera en que cada emisor se posiciona discursivamente en un proceso de esta índole, lo que depende en gran medida de la cultura que cada uno de los emisores posee, de su visón del mundo, de las intenciones en un intercambio de comunicación de esta índole.

A manera de reflexión, se concluye que en el desarrollo de una competencia para leer críticamente e interpretar en un acto comunicativo, se debe comprender e interpretar no sólo la dimensión semántica; es decir, lo que está un tanto explícito en las líneas, o lo que se infiere o puede inferirse, sino las intenciones, esto es, las cuestiones pragmáticas del discurso, su rol social en la comunidad, y cómo se concibe en la disciplina en la que se redacta el texto.

En este discurso, como se ha afirmado, al ser un discurso eminentemente cortés, se deben estudiar y tomar conciencia de las estrategias de atenuación, los recursos de la (des) cortesía, así como de la intensificación y de su impacto semántico y pragmático; además de desarrollar la habilidad para reconocerlos e interpretarlos cuando se presentan en el acto ilocutivo de un proceso jurídico.

En relación con estas formas de enunciación, Albelda (2005) ${ }^{61}$ y Briz (2001) ${ }^{62}$, afirman que la principal función de la intensificación es hacer que algo tenga mayor intensidad para conseguir persuadir y convencer al interlocutor. Este recurso se ve claramente representado en la sentencia de adopción, en la cual los demandantes usan el léxico que es representado en las categorías gramaticales que cumplen esas funciones: sustantivos que maximizan el actuar del juez, y los adjetivos, frases adverbiales y adjetivales para convencer el actuar del juez hacia su proceso de demanda. En relación con esto, Albelda (2005: 28), afirma que gramaticalmente no existe una alusión directa al concepto de intensificación; sólo se alude a ésta a través de la gradación de los elementos morfológicos que cumplen este cometido, por

61 Albelda M. (2005). La intensificación en el español coloquial. Universidad de Valencia.

62 Briz, A. (2001). El español coloquial en la conversación. Esbozo de pragmagramática. Editorial Ariel. 2a Edición. Barcelona España. 
lo que, a nivel lingüístico, no existe una definición puntual sobre la intensificación, sino que se hace referencia a ésta como un fenómeno de cuantificación, gradación y superlación, que representan claramente lo que es la estrategia de la intensificación.

En el corpus de sentencias que se ha analizado en esta investigación, se pudo apreciar cómo los involucrados en un proceso de demanda en donde se resuelve a través de una sentencia, hacen uso constante de un lenguaje cortésmente atenuado, el cual les permite resguardar la imagen a través de las diferentes estrategias a las que recurren los juristas y el uso de la palabra. Aquí se puede observar la intención de quien emite un mensaje, por una parte, de los jueces, y por otra de los promoventes o participantes en el discurso de las sentencias.

\section{BIBLIOGRAFÍA}

Albelda M. (2005). La intensificación en el español coloquial. Universidad de Valencia.

Albelda Marco, M. (2005). Discordancia entre atenuación/ cortesía e intensificación/descortesía en conversaciones coloquiales. En Blas, J.L. Casanova, M., Velando M (eds): Discurso y Sociedad. Contribuciones al estudio de la lengua en contexto social, Servicio publicaciones de la Universidad de Castellón, pp. 581-590

Alcaraz Varó, E., \& Hughes, B. (2002). El español jurídico. Barcelona: Ariel.

Alcaraz, Varó, E. (1994). El inglés jurídico: Textos y documentos. Barcelona: Ariel.

Archer, D. (2011). Facework and im/politeness across legal contexts: An introduction. Journal of Politeness Research, n. 7, p. 1-19, 2011.

Baran, M. (2010). Emotividad y convención sociopragmática. Una contribución al estudio del ethos comunicativo de la comunidad hispanohablante peninsular. Polonia: Universidad de Łódź.

Bernal, M. (2010). Descortesía en el contexto judicial. El caso del juicio del 11-M. En F. Orletti y L. Mariottini (Eds.), (Des) cortesía en español. Espacios teóricos y metodológicos para su estudio (pp. 599-636). Roma-Estocolmo: Università degli Studi Roma Tre-EDICE.

Borja Albi, Anabel. (2000). El texto jurídico inglés y su traducción al español. Barcelona: Ariel Lenguas Modernas.

Bravo, D. (1999). ¿Imagen 'positiva' vs imagen 'negativa'?: Pragmatica sociocultural y componentes de face. Oralia. Analisis del Discurso Oral.

Bravo, D. (2004). Actividades de cortesía, imagen social y contextos socioculturales: Una introducción. Actas del Primer Coloquio del programa EDICE. Estocolmo: Programa EDICE.

Bravo, D., Flores N. H., y Cordisco, A. (eds). (2010). Aportes pragmáticas sociopragmáticas y socioculturales de la cortesía en español. Estocolmo / Buenos Aires: Dunken.

Briz Gómez, Antonio. (1995). La conversación coloquial. Anejo XVI de la revista Cuadernos de Filología. Universidad de Valencia.

Briz, A. (2001). El español coloquial en la conversación. Esbozo de pragmagramática. Editorial Ariel. 2a Edición. Barcelona España.

Briz Gómez, Antonio. (2003). La estrategia atenuadora en la conversación cotidiana española, en D. Bravo (ed.) (2003a), pp. 17 - 46.

Briz Gómez, Antonio. (2007). Para un análisis semántico, progmático y sociopragmático de la cortesía atenuadora en España y América. Lingüística Española Actual XXIX/1.

Briz Gómez A. (2012). La (no) atenuación y la (des)cortesía, lo lingüístico y social: ¿son pareja? En J. Escamilla Morales y G. H. Vega (Eds.), Miradas Multidisciplinarias a los fenómenos de cortesía y descortesía en el mundo hispánico. Barranquilla/Estocolmo: CADIS-Programa EDICE.

Brown \& Levinson (1987). Politeness: Some universals in language usage. Cambridge.

Cubells e Iñiguez-Rueda (2008). La construcción de hechos en el discurso jurídico: Análisis del caso de los robos en 
cajeros automáticos en la ciudad de Barcelona. Revista Española de Investigación Criminológica Artículo 4, Número 6

Escandell, V. (1996). Introducción a la pragmática. Barcelona, Editorial Ariel, S.A.

Flores Hernández, N. (2002). La cortesia en la conversación Española de familiares y amigos: La búsqueda de equilibrio entre la imagen del hablante y la imagen del destinatario. Programa EDICE.

Fuentes, C. (2011). (Des)cortesía y violencia verbal: implicaciones lingüísticas y sociales. Aproximaciones a la (des) cortesía verbal en español. E. R. A. Lara, \& E. B. Peña (Eds.). Peter Lang. 27-64.

Held, G. (1989). On the role of maximization in verbal politeness, Multilingua 8-2/3, pp. 167-206.

Kaul de Marlangeon, S.(2005). Descortesía de fustigación por afiliación exacerbada o refractariedad. En D. Bravo (Ed.), Estudios de la (des) cortesía en español. Categorías conceptuales y aplicaciones a corporas orales y escritos. Vol I, pp 299-318). Buenos Aires: Programa EDICE- Dunken.

Kaul de Marlangeon, S. (2012). Encuadre de aspectos teórico-metodológicos de la descortesía verbal en español. Miradas multidisciplinares de los fenómenos de cortesía y descortesía en el mundo hispánico, en Escamilla Morales J. y Vega G. H. (eds.) Universidad del Atlantico y programa EDICE, 76.

Kryk-kastovsky, B. (2006) Impoliteness in early modern in English courtroom discourse. Journal of Historical Prgamatic. John Benjamins.

Lachenicht L. G. (1980). Aggravating language: A study of abusive and insulting language. Paper in Linguistics.

Leech, G. (1983). Principles of Pragmatics. New York: Longman Group Ltda.

Morris, C. (1985). Fundamentos de la teoría de los signos. Barcelona: Paidós.

Saiz Pérez, I. (2004). La adquisición de la competencia sociopragmática. ¿Son las estancias en el extranjero la clave de su éxito? Tesina, Universidad de Estocolmo.

Spencer-Oatey, H. (2000). Culturally speaking managing rapport in talk across cultures. London: Cassell.
Thomas. J. (1983). Cross-cultural pragmatic failure. Applied linguistics, 4(2), 91-112

Vigara Tauste, Ana María (1992). Morfosintaxis del español coloquial (Esbozo estilístico). Madrid, Gredos 
